\title{
Mitochondrial DNA control region variation in a population sample from Thailand
}

\author{
Dirk Christopher Sauer $^{1,2} \cdot$ Jana Naue $^{1,2}$ (D) - Uta-Dorothee Immel ${ }^{3,4} \cdot$ Sabine Lutz-Bonengel ${ }^{1,2}$ (D)
}

Received: 6 March 2020 / Accepted: 14 April 2020 / Published online: 1 May 2020

(C) The Author(s) 2020

\begin{abstract}
Mitochondrial DNA (mtDNA) control region sequences from hair samples of 213 individuals from Thailand were analyzed using Sanger sequencing. A total of 170 different haplotypes were identified, of which 146 occurred only once (unique haplotypes). The dataset showed a random match probability of $0.87 \%$ and a haplotype diversity of 0.9960 . The samples were assigned to 85 different haplogroups with B5a, F1a1a, and M being the most frequent ones. Pairwise $\mathrm{F}_{\mathrm{ST}}$-values between this and other Southeast and East Asian populations revealed significant but relatively low differences, indicating a close relation. Heteroplasmic positions were observed in $12.2 \%$ of hair samples confirming the frequent appearance of heteroplasmic positions in hairs. This dataset will complement existing data as an mtDNA reference for forensic investigations.
\end{abstract}

Keywords Mitochondrial DNA $\cdot$ Control region $\cdot$ Thailand $\cdot$ Haplogroup $\cdot$ Forensic database

\section{Introduction}

Mitochondrial DNA (mtDNA) analysis has become a routine approach in forensic casework where STR markers cannot be used. The associated estimation of the frequency of obtained mtDNA profiles in the respective population sample is based on the availability of suitable population data sets. MtDNA data from Thailand has already been published [1-5].

\section{Highlights}

- High-quality mtDNA reference data for 213 hair samples of Thailand were collected

- A total of 170 different haplotypes were observed belonging to macrohaplogroups $\mathrm{R}, \mathrm{M}$, and $\mathrm{N}$ (except of one)

- A random match probability of $0.87 \%$ and a haplotype diversity of 0.9960 was found

- Results were compared with six other studies from Southeast and East Asian population samples

- Heteroplasmic positions were found in $12.2 \%$ of hair samples

Electronic supplementary material The online version of this article (https://doi.org/10.1007/s00414-020-02303-2) contains supplementary material, which is available to authorized users.

Sabine Lutz-Bonengel

sabine.lutz-bonengel@uniklinik-freiburg.de

1 Institute of Forensic Medicine, Medical Center - University of Freiburg, Forensic Molecular Biology, Albertstrasse 9, 79104 Freiburg, Germany
However, these datasets either are limited to SNPs in the mitochondrial hypervariable regions 1 and 2 [1] or the collection strategy focuses on a different priority, such as language [2-4]. Furthermore, a forensic study on a population from Thailand was done in the northern province of Chiang Mai [5]. Given that the population of Thailand is composed of different ethnolinguistic groups [6], a regional population sample cannot be considered to be representative for the whole country.
2 Faculty of Medicine, University of Freiburg, Freiburg, Germany

3 Institute of Legal Medicine, Johannes Gutenberg-University Mainz, Am Pulverturm 3, 55131 Mainz, Germany

4 Institute of Legal Medicine, Martin-Luther-University Halle-Wittenberg, Franzosenweg 1, 06114 Halle, Germany 
In this paper, we present a population dataset of 213 individuals living in all four major regions of Thailand.

\section{Materials and methods}

\section{Samples}

Hair samples were obtained from 213 unrelated individuals of both sexes living in southern, central, northern, and northeastern Thailand (Fig. 1, Supplementary Table S1). The samples were collected from volunteer donors and anonymized. Written informed consent was obtained from all participants. Ethical approval for mtDNA sequencing analysis was given

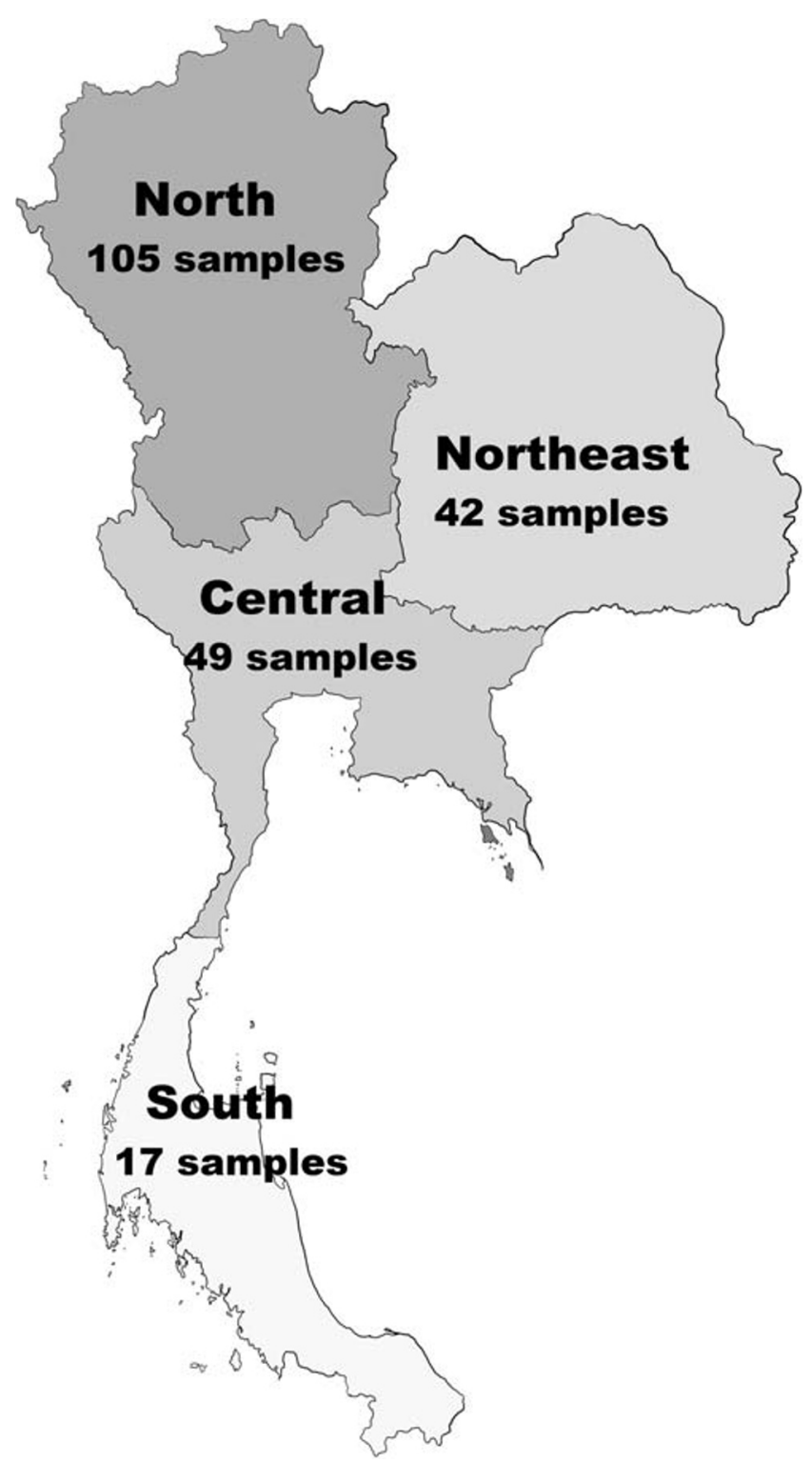

Fig. 1 Schematic map of Thailand. The four major regions of Thailand and number of collected samples from each region are provided by the Ethics Committee of the University of Freiburg, Germany (398/16).

\section{DNA extraction, amplification, and sequencing}

Total DNA of 10-12 hairs per individual was extracted with the MagCore ${ }^{\circledR}$ Genomic DNA Tissue Kit (RBC Bioscience, New Taipei City, Taiwan) at the University of Khon Kaen (Khon Kaen, Thailand). PCR and sequencing of the entire control region were performed at the University Medical Center Freiburg - University of Freiburg (Freiburg, Germany) as described in [7] using primers given in Supplementary Tables S2 and S3.

\section{Sequence analysis and haplogroup assignment}

A total of 213 full double strand control region sequences were successfully analyzed and aligned to the revised Cambridge Reference Sequence (rCRS) [8, 9] using Sequencher V5.2.2 (GeneCodes, Ann Arbor, MI, USA). Alignment was done according to the revised and extended guidelines of the ISFG [10]. Haplogroups were assigned with Haplogrep 2 (www.haplogrep.uibk.ac.at) [11] and EMPOP v4/R12 (www.empop.online) [12] based on PhyloTree, build 17 [13]. Assignments were revised manually and conservative estimates of most recent common ancestors (MRCA) were chosen.

MtDNA data quality was controlled using the EMPOP tool NETWORK [14]. Further quality control was done by the team of EMPOP at Medical University of Innsbruck. All 213 sequences are incorporated into the EMPOP database under the accession number EMP00699.

\section{Statistical analysis}

Intra- and inter-population statistical analysis was done using Arlequin v3.5.2.2 [15]. Numbers of different and unique haplotypes were counted and genetic diversity indices of the population (random match probability, haplotype diversity, number of polymorphic positions, mean number of pairwise differences, and nucleotide diversity) were calculated. Length variants at nucleotide positions 16193, 309, and 573 were ignored for statistical tests. Random match probability was calculated as the sum of squared haplotype frequencies.

We compared our data with six other Southeast and East Asian populations from recent studies [5, 16-20] only considering control region data (np 16024-576). We performed a molecular variance analysis (AMOVA) and calculated genetic diversity indices for the additional included studies, pairwise differences between and within populations, and pairwise $\mathrm{F}_{\mathrm{ST}^{-}}$ values. 
Table 1 Molecular diversity indices for mtDNA control region data of a population sample from Thailand

\begin{tabular}{ll}
\hline Population statistics* & Thailand $(n=213)$ \\
\hline Number of different haplotypes & 170 \\
Unique haplotypes; portion of samples & $146(68.5 \%)$ \\
Random match probability & $0.87 \%$ \\
Haplotype diversity & $0.9960 \pm 0.0013$ \\
Number of polymorphic positions (including & 196 of 1134 \\
$\quad$ indels) & $12.86 \pm 5.82$ \\
Mean number of pairwise differences & $0.011337 \pm 0.005674$ \\
Nucleotide diversity &
\end{tabular}

*Insertions at nucleotide positions 16193, 309, and 573 were disregarded

\section{Results and discussion}

We obtained 213 high-quality mtDNA control region sequences from Thailand to establish reference data (Supplementary Table S1). Summary statistics are presented in Table 1. From a total of 170 different haplotypes, 146 were unique. The population sample had a random match probability of $0.87 \%$ and a haplotype diversity of $0.9960 \pm 0.0013$ revealing a high heterogeneity in the population making it useful for forensic analyses.

We compared the detected haplotypes with those of six earlier studies of Southeast and East Asian populations including one with samples from Northern Thailand [5, 16-20]. A total of 44 of the 170 haplotypes $(25.9 \%)$ were found in at least one other population (Supplementary Table S4). Accordingly, 126 haplotypes $(74.1 \%)$ of our study were not observed in the other studies, including the most common haplotype of our study (9 samples) (cf. Supplementary Table S1).

\section{Haplogroup composition}

The 213 samples from Thailand were assigned to 85 different haplogroups (Supplementary Table S1). Some sequences could not be classified to a terminal branch of the PhyloTree [13] and were assigned to their MRCA such as macrohaplogroup $\mathrm{M}(8.9 \%)$. The most frequent terminally assigned haplogroups were B5a (9.4\%), F1a1a (8.9\%), and $\mathrm{M}(8.9 \%)$. All samples belong to macrohaplogroups $\mathrm{R}(50.7 \%), \mathrm{M}(39.4 \%)$, and $\mathrm{N}$ (9.4\%) except of one sample which could only be assigned to L3 as MRCA.

In general, the haplogroup composition is comparable with other Southeast Asian population samples with F1, B5, and M being the most frequent lineages $[2,4,5,16-19]$.

\section{Genetic distances between Southeast and East Asian populations}

We compared the genetic structures of our population sample from Thailand with the six other Southeast and East Asian population samples [5, 16-20]. The total number of samples was 1789. Analysis of molecular variance (AMOVA) revealed that $98.06 \%$ of the genetic variation is due to differences within populations. Thus, only $1.94 \%$ of the total genetic variance is caused by differences between populations (Table 2). Bodner et al. (2011) had found an inter-population variance of only $0.84 \%$ in a very similar dataset, but only considering hypervariable regions (HVS-I and HVS-II) and a regional restricted population [16].

The number of mean pairwise differences (MPD) in the Thai population is 12.86 , which is in the dimension of that observed in other Asian populations (Table 3). The lowest MPD value (11.75) was observed in a South Korean population, the highest (13.42) in Northern Thailand.

Pairwise $\mathrm{F}_{\mathrm{ST}^{-}}$-values between population samples were relatively low and similar, indicating a close relation between populations. Higher variance was found between Southeast Asian populations (Thailand, Northern Thailand, Laos, Northern Vietnam, and Myanmar) and South Korea ( $\mathrm{F}_{\mathrm{ST}}$ 0.037-0.051), whereas genetic variance between Hong Kong and South Korea was low ( $F_{S T}$ 0.016). All $F_{S T}$-values between Thailand and other population samples were significant (Table 4).
Table 2 Analysis of molecular variance (AMOVA) of 7 Southeast and East Asian populations (analyzed range: np 16024 576). AMOVA design and results

\begin{tabular}{lcccc}
\hline Source of variation & Degrees of freedom & Sum of squares & Variance components & $\begin{array}{l}\text { Percentage of } \\
\text { variation }\end{array}$ \\
\hline Among populations & 6 & 229.238 & $0.12603^{\mathrm{b}}$ & $1.94^{\mathrm{a}, \mathrm{b}}$ \\
Within populations & 1782 & $11,375.467$ & 6.38354 & 98.06 \\
Total & 1788 & $11,604.705$ & 6.50957 & \\
\hline
\end{tabular}

${ }^{\text {a }}$ Corresponds to $\mathrm{F}_{\mathrm{ST}}$ of 0.0194

${ }^{\mathrm{b}} p$ value $<0.001$, number of permutations: 1023 
Table 3 Analysis of molecular variance (AMOVA) of 7 Southeast and East Asian populations (analyzed range: np 16024-576). Mean number of pairwise differences (MPD) between seven Southeast and East Asian populations

\begin{tabular}{|c|c|c|c|c|c|c|c|}
\hline Population & Thailand & Northern Thailand & Laos & Northern Vietnam & Myanmar & Hong Kong & South Korea \\
\hline Reference & This study & {$[5]$} & {$[16]$} & {$[17]$} & {$[18]$} & [19] & {$[20]$} \\
\hline Thailand & 12.86 & 13.19 & 13.07 & 12.91 & 12.75 & 13.17 & 12.85 \\
\hline Northern Thailand & 0.05 & 13.42 & 13.40 & 13.20 & 13.09 & 13.36 & 13.07 \\
\hline Laos & 0.05 & 0.09 & 13.18 & 13.00 & 13.07 & 13.33 & 13.07 \\
\hline Northern Thailand & 0.07 & 0.07 & $-0.01 *$ & 12.83 & 12.87 & 13.10 & 12.83 \\
\hline Myanmar & 0.10 & 0.15 & 0.25 & 0.24 & 12.45 & 13.10 & 12.75 \\
\hline Hong Kong & 0.17 & 0.07 & 0.16 & 0.11 & 0.30 & 13.16 & 12.65 \\
\hline South Korea & 0.55 & 0.48 & 0.60 & 0.54 & 0.65 & 0.20 & 11.75 \\
\hline
\end{tabular}

Above diagonal: Average number of pairwise differences between populations ( $\widehat{\Pi} \mathrm{XY})$

Diagonal elements: Average number of pairwise differences within population $(\widehat{\Pi} \mathrm{X})$

Below diagonal: Corrected average pairwise difference $(\widehat{\Pi} \mathrm{XY}-(\widehat{\Pi} \mathrm{X}+\widehat{\Pi} \mathrm{Y}) / 2)$

*Corrected $p$ value $>0.05$

\section{Heteroplasmy}

We observed a total of 27 point heteroplasmies at 14 different positions in 26 hair samples (12.2\%) (Supplementary Table S5). In a former study including 691 hair shaft samples, the frequency of point heteroplasmy was $11.4 \%$ [21]. Based on other studies using various types of tissue material, in Southeast and East Asian populations, the percentage of samples with point heteroplasmy was calculated as follows: Northern Thailand 2.6\% (blood), Laos 3.7\% (blood), Hong Kong $8.5 \%$ (blood), Myanmar $8.6 \%$ (blood), South Korea $10.3 \%$ (blood and buccal swabs), and Northern Vietnam $15.0 \%$ (buccal swabs) $[5,16-20]$. These values confirm that mtDNA heteroplasmy frequency is dependent on the analyzed tissue as specified in [7]. However, it has to be considered that low level heteroplasmic positions were not detected using Sanger sequencing.

\section{Conclusion}

The sample of $213 \mathrm{mtDNA}$ control region sequences will serve as a high-quality mtDNA reference for Thailand. Most of the detected haplotypes were unique within the known data and will complement the available data from Northern Thailand [5] and other Southeast Asian populations.

Recently, 960 complete mtDNA genomes from Thailand originally sequenced to investigate anthropologic questions [4] were also incorporated into the EMPOP database [14]. The increasing data of Southeast Asian mtDNA sequences is leading to a reliable forensic reference for this region.

Acknowledgments Open Access funding provided by Projekt DEAL. We would like to thank Arisa Sanubol and Tikumporn Thooptianrat of Khon Kaen University, Thailand, for sample collection and DNA extraction. Furthermore, we thank Chaveerach Arunrat and Sudmoon Runglawan of Khon Kaen University, Thailand, for the support and their

Table 4 Analysis of molecular variance (AMOVA) of 7 Southeast and East Asian populations (analyzed range: np 16024-576). Population pairwise $\mathrm{F}_{\mathrm{ST}}$-values

\begin{tabular}{llllllll}
\hline Population: & Thailand & Northern Thailand & Laos & Northern Vietnam & Myanmar & Hong Kong & South Korea \\
\hline Reference: & This study & {$[5]$} & {$[16]$} & {$[17]$} & {$[18]$} & {$[19]$} & {$[20]$} \\
Thailand & $*$ & 0.004 & 0.004 & 0.005 & 0.008 & 0.013 & 0.043 \\
Northern Thailand & 0.027 & $*$ & 0.007 & 0.005 & 0.012 & 0.005 & 0.037 \\
Laos & 0.028 & 0.006 & $*$ & -0.001 & 0.019 & 0.012 & 0.046 \\
Northern Vietnam & 0.015 & 0.012 & 0.598 & $*$ & 0.018 & 0.008 & 0.023 \\
Myanmar & 0.000 & 0.000 & 0.000 & 0.000 & 0.000 & $*$ & 0.051 \\
Hong Kong & 0.000 & 0.004 & 0.000 & 0.000 & 0.000 & 0.000 & 0.016 \\
South Korea & 0.000 & 0.000 & 0.000 & 0.000 & $*$ & \\
\hline
\end{tabular}

Above diagonal: Population pairwise $\mathrm{F}_{\mathrm{ST}}$-values

Below diagonal: $p$ values (significance level $=0.05$; number of permutations: 1023 ) 
assistance at Khon Kaen University, and Rüdiger Lessig of the Martin Luther University, Halle-Wittenberg, Germany, for the support of the research project. We also thank Walther Parson and Nicole Huber of the Medical University of Innsbruck for quality control of the mtDNA sequences and assistance with haplogroup assignment.

Authors' contributions All authors contributed to the study conception and design. UI collected the samples and extracted the DNA. DS performed mtDNA analysis, statistical analysis, and drafted the manuscript. $\mathrm{JN}$ evaluated the analysis and revised the manuscript. SLB designed the study. All authors contributed to the manuscript and approved the final version.

Data availability All haplotypes are provided in the supplementary materials and were provided to EMPOP under the accession number EMP00699.

\section{Compliance with ethical standards}

Conflict of interest The authors declare that they have no conflict of interest.

Ethics approval Ethical approval for mtDNA sequencing analysis was given by the Ethics Committee of the University of Freiburg, Germany (398/16).

Research involving human participants All procedures performed in studies involving human participants were in accordance with the ethical standards of the Ethical Committee of Faculty of Medicine, University of Freiburg, no. 398/16 and with the 1964 Helsinki declaration and its later amendments or comparable ethical standards.

Consent to participate (include appropriate statements) Informed consent was obtained from all individual participants included in the study.

Consent for publication (include appropriate statements) The participants have consented to the submission of analyzed DNA results as anonymous data.

Open Access This article is licensed under a Creative Commons Attribution 4.0 International License, which permits use, sharing, adaptation, distribution and reproduction in any medium or format, as long as you give appropriate credit to the original author(s) and the source, provide a link to the Creative Commons licence, and indicate if changes were made. The images or other third party material in this article are included in the article's Creative Commons licence, unless indicated otherwise in a credit line to the material. If material is not included in the article's Creative Commons licence and your intended use is not permitted by statutory regulation or exceeds the permitted use, you will need to obtain permission directly from the copyright holder. To view a copy of this licence, visit http://creativecommons.org/licenses/by/4.0/.

\section{References}

1. Thongngam $\mathrm{P}$, Leewattanapasuk $\mathrm{W}$, Bhoopat T, Sangthong $\mathrm{P}$ (2017) Single nucleotide polymorphisms minisequencing in hypervariable regions for screening of Thais. Gene 627:538-542. https:// doi.org/10.1016/j.gene.2017.07.008

2. Kutanan W, Kampuansai J, Brunelli A, Ghirotto S, Pittayaporn P, Ruangchai S, Schröder R, Macholdt E, Srikummool M, Kangwanpong D, Hübner A, Arias L, Stoneking M (2018) New insights from Thailand into the maternal genetic history of
Mainland Southeast Asia. Eur J Hum Genet 26:898-911. https:// doi.org/10.1038/s41431-018-0113-7

3. Kutanan W, Kampuansai J, Changmai P, Flegontov P, Schröder R, Macholdt E, Hübner A, Kangwanpong D, Stoneking M (2018) Contrasting maternal and paternal genetic variation of huntergatherer groups in Thailand. Sci Rep 8:1536. https://doi.org/10. 1038/s41598-018-20020-0

4. Kutanan W, Kampuansai J, Srikummool M, Kangwanpong D, Ghirotto S, Brunelli A, Stoneking M (2017) Complete mitochondrial genomes of Thai and Lao populations indicate an ancient origin of Austroasiatic groups and demic diffusion in the spread of Tai-Kadai languages. Hum Genet 136:85-98. https://doi.org/ 10.1007/s00439-016-1742-y

5. Zimmermann B, Bodner M, Amory S, Fendt L, Röck A, Horst D, Horst B, Sanguansermsri T, Parson W, Brandstätter A (2009) Forensic and phylogeographic characterization of mtDNA lineages from northern Thailand (Chiang Mai). Int J Legal Med 123:495501. https://doi.org/10.1007/s00414-009-0373-4

6. Eberhard DM, Simons GF, Fennig CD (2019) (Eds.), Ethnologue: languages of the world, $22^{\text {nd }}$ ed., SIL International, Dallas, Texas

7. Naue J, Hörer S, Sänger T, Strobl C, Hatzer-Grubwieser P, Parson W, Lutz-Bonengel S (2015) Evidence for frequent and tissuespecific sequence heteroplasmy in human mitochondrial DNA. Mitochondrion 20:82-94. https://doi.org/10.1016/j.mito.2014.12. 002

8. Andrews RM, Kubacka I, Chinnery PF, Lightowlers RN, Turnbull DM, Howell N (1999) Reanalysis and revision of the Cambridge reference sequence for human mitochondrial DNA. Nat Genet 23: 147

9. Anderson S, Bankier AT, Barrell BG, de Bruijn MHL, Coulson AR, Drouin J, Eperon IC, Nierlich DP, Roe BA, Sanger F, Schreier PH, Smith AJH, Staden R, Young IG (1981) Sequence and organization of the human mitochondrial genome. Nature 290:457-465

10. Parson W, Gusmão L, Hares DR, Irwin JA, Mayr WR, Morling N, Pokorak E, Prinz M, Salas A, Schneider PM, Parsons TJ (2014) DNA Commission of the International Society for Forensic Genetics: revised and extended guidelines for mitochondrial DNA typing. Forensic Sci Int Genet 13:134-142. https://doi.org/10.1016/ j.fsigen.2014.07.010

11. Weissensteiner H, Pacher D, Kloss-Brandstätter A, Forer L, Specht G, Bandelt H-J, Kronenberg F, Salas A, Schönherr S (2016) HaploGrep 2: mitochondrial haplogroup classification in the era of high-throughput sequencing. Nucleic Acids Res 44(W1):W58 W63. https://doi.org/10.1093/nar/gkw233

12. Huber N, Parson W, Dür A (2018) Next generation database search algorithm for forensic mitogenome analyses. Forensic Sci Int Genet 37:204-214. https://doi.org/10.1016/j.fsigen.2018.09.001

13. van Oven M, Kayser M (2009) Updated comprehensive phylogenetic tree of global human mitochondrial DNA variation. Hum Mutat 30:E386-E394. https://doi.org/10.1002/humu.20921

14. Parson W, Dür A (2007) EMPOP - a forensic mtDNA database. Forensic Sci Int Genet 1:88-92. https://doi.org/10.1016/j.fsigen. 2007.01.018

15. Excoffier L, Lischer HEL (2010) Arlequin suite ver 3.5: a new series of programs to perform population genetics analyses under Linux and Windows. Mol Ecol Resour 10:564-567. https://doi.org/ 10.1111/j.1755-0998.2010.02847.x

16. Bodner M, Zimmermann B, Röck A, Kloss-Brandstätter A, Horst D, Horst B, Sengchanh S, Sanguansermsri T, Horst J, Krämer T, Schneider PM, Parson W (2011) Southeast Asian diversity: first insights into the complex mtDNA structure of Laos. BMC Evol Biol 11:49. https://doi.org/10.1186/1471-2148-11-49

17. Irwin JA, Saunier JL, Strouss KM, Diegoli TM, Sturk KA, O'Callaghan JE, Paintner CD, Hohoff C, Brinkmann B, Parsons TJ (2008) Mitochondrial control region sequences from a 
Vietnamese population sample. Int J Legal Med 122:257-259. https://doi.org/10.1007/s00414-007-0205-3

18. Summerer M, Horst J, Erhart G, Weißensteiner H, Schönherr S, Pacher D, Forer L, Horst D, Manhart A, Horst B, Sanguansermsri T, Kloss-Brandstätter A (2014) Large-scale mitochondrial DNA analysis in Southeast Asia reveals evolutionary effects of cultural isolation in the multi-ethnic population of Myanmar. BMC Evol Biol 14:17. https://doi.org/10.1186/1471-2148-14-17

19. Irwin JA, Saunier JL, Beh P, Strouss KM, Paintner CD, Parsons TJ (2009) Mitochondrial DNA control region variation in a population sample from Hong Kong. China, Forensic Sci Int Genet 3:e119 e125. https://doi.org/10.1016/j.fsigen.2008.10.008
20. Scheible M, Kim SH, Sturk-Andreaggi K, Coble MD, Irwin JA (2014) Mitochondrial control region variation in a Korean population sample. Int J Legal Med 128:745-746. https://doi.org/10.1007/ s00414-014-0963-7

21. Melton T, Dimick G, Higgins B, Lindstrom L, Nelson K (2005) Forensic mitochondrial DNA analysis of 691 casework hairs. J Forensic Sci 50:73-80

Publisher's note Springer Nature remains neutral with regard to jurisdictional claims in published maps and institutional affiliations. 